\title{
Size and Operating Profitability Portfolio Returns and Return Premia in Japan-A Tour d'horizon
}

\author{
Chikashi Tsuji \\ Professor, Faculty of Economics, Chuo University \\ 742-1 Higashinakano, Hachioji-shi, Tokyo 192-0393, Japan \\ E-mail:mail_sec_low@minos.ocn.ne.jp
}

Received: March 22, 2021 Accepted: April 1, 2021 Published: April 2, 2021

doi:10.5296/jmr.v13i2.18441ＵRL: https://doi.org/10.5296/jmr.v13i2.18441

\begin{abstract}
This study examines the Japanese equity returns and return premia by focusing on firm sizeand corporate operating profitability-sorted portfolios over the period from 1990 to 2020. As a result of our explorations, this study derives the following much beneficial findings. (1) The effects of corporate operating profitability and firm size are generally continuously seen in the Japanese equity market. More specifically, (2) the size effect is much stronger in our latter half sub-period; while the operating profitability effect is similarly seen in both our former half and latter half sub-periods. Furthermore, (3) we stress that this study employs the data in US dollars, and calculates several key statistics and measures for not only our full sample period but also many different sub-periods, in which economic and business circumstances are much different. Therefore, for both Japanese and international equity investors, our findings shall be highly useful for enriching and furthering the understanding of returns and return premia of Japanese equity portfolios.
\end{abstract}

Keywords: Japanese equity market, operating profitability, portfolio return, return premia, size effect 


\section{Introduction}

Research of the performance of size- and operating profitability-sorted portfolios is crucial since size and operating profitability are key elements for effective quantitative portfolio constructions (see, e.g., Fama and French, 2015; Lin, 2017; Chen and Ho, 2020). However, for the Japanese equity market, little research from this perspective can be found in previous studies; therefore, to take a brief look at size and operating profitability portfolios of Japanese equities carefully is extremely meaningful. Based on this motivation, this study attempts to conduct an effective overview of Japanese equity returns and return premia over the period from 1990 through to 2020 by focusing on size- and operating profitability-sorted portfolios.

As a result of our explorations, this study derives the following quite beneficial findings. (1) The effects of operating profitability and size are generally continuously seen in the Japanese equity market. More specifically, (2) the size effect is much stronger in our latter half subperiod; while the operating profitability effect is similarly seen in both our former half and latter half sub-periods. Moreover, (3) we emphasize that this study employs the data in US dollars, and calculates several important statistics for not only our full period but also many sub-periods, in which economic and business circumstances are much different. Hence, for both Japanese and international equity investors, the findings from our study shall be highly useful for enriching the understanding of returns and return premia of Japanese equity portfolios.

The organization of the rest of this paper is as follows. Section 2 conducts a brief review of related past literature; Section 3 provides our data and methodology; Section 4 supplies our main findings; and Section 5 exhibits our conclusions.

\section{Related Literature Review}

This section briefly conducts a related literature review. After Fama and French (1993) showed the importance of the value and size effects in the US with presenting their three-factor model, many studies have analyzed the value and size effects and the validity of their value and size factors. For example, in international equity markets, Fama and French (2012) tested the value, size, and momentum effects; and in the US, Tsuji (2012a) examined whether industry equity returns contain predictive information for the Fama-French three factors.

As regards Japan, Chan et al. (1991) investigated the relationships between cross-sectional returns of Japanese equities and the cash flow yield, earnings yield, size, and book-to-market (BM) ratio. Later, Tsuji (2012b) studied Japanese size- and BM-sorted portfolios for the period from 1981 to 2005, and evidenced the positive return premia uncaptured by the Fama-French three-factor model. It is noted that the Japanese equity portfolio analysis with being in accordance with the Fama-French style and covering more recent periods is very limited.

Afterwards, Fama and French (2015) developed a five-factor asset pricing model, including corporate operating profitability and firms' investment. Introducing related studies, Ülkü (2017) examined the Monday effect in the Fama-French's operating profitability factor. Leite et al. (2020) investigated the relations between the five-factors, interest rates, and macro variables. Lin (2017) tested the effectiveness of the five-factor model in China. Chen and Ho (2020) 
examined the performance of the five-factor model under different market sentiments, and Jareño et al. (2020) analyzed the five-factor model in Europe.

However, as above, it is emphasized that there is little research that focused on the operating profitability of the Fama-French five-factor model in Japan. Hence highly importantly, this study below examines the effect of the operating profitability alongside the classic size effect in Japan with covering very recent periods.

\section{Data and Research Design}

In this section, we first describe our data. All of our basic data as to Japanese equity portfolios, which we use for our research, are percentage returns in US dollars. All the data were provided by Fama and French. More concretely, (1) Mkt means the market portfolio; (2) Small-Low OP means the small-sized and low operating profitability portfolio; and (3) Small-Middle OP means the small-sized and neutral (middle) operating profitability portfolio. Further, (4) SmallHigh OP means the small-sized and high operating profitability portfolio; (5) Big-Low OP means the big-sized and low operating profitability portfolio; (6) Big-Middle OP means the big-sized and neutral (middle) operating profitability portfolio; and (7) Big-High OP means the big-sized and high operating profitability portfolio. It is noted that we employ simple statistical and graphical analysis for our research design.

In this study, we first investigate (1) our full sample period of July 1990 to October 2020. We next analyze (2) our former half sub-sample period of July 1990 to December 2005; and we then examine (3) our latter half sub-sample period of January 2006 to October 2020.

Subsequently, this paper further investigates six five-year sub-periods and the latest sub-period. Our six five-year sub-periods are (1) from July 1990 to June 1995, comprising the collapse of stock price bubble in Japan; (2) from July 1997 to June 2002, comprising the IT bubble; and (3) from January 2002 to December 2006, in which Japan's Quantitative Easing (QE) monetary policy advanced Japanese equity prices. Further, the rest of our five-year sub-periods are (4) from January 2007 to December 2011, comprising the US subprime crisis and the collapse of Lehman Brothers; (5) from April 2010 to March 2015, comprising the Great East Japan Earthquake; and finally, (6) from April 2015 to March 2020, comprising successive monetary easing policies executed by the Bank of Japan (BOJ). In addition, our latest sub-period is (7) from January 2020 to October 2020, although this seventh sub-period is not a five-year period.

Figure 1 exhibits the cumulative raw return evolution of the above six Japanese size and operating profitability portfolios and that of the market portfolio. In this figure, Panel A exhibits the evolution for our full period, Panel B exhibits the evolution for our former half sub-period, and Panel $\mathrm{C}$ shows that for our latter half sub-period. In Panels A and B, all the stock prices are set at 100 in July 1990, while in Panel C, all the prices are set at 100 in January 2006.

Moreover, Figure 2 exhibits the cumulative return premia evolution of the above six size and operating profitability portfolios over the market portfolio. In Figure 2, Panel A exhibits the evolution for our full period, Panel B exhibits that for our former half sub-period, and Panel C exhibits that for our latter half sub-period. In Panels A and B, all the return premia are set at zero in July 1990, while in Panel C, those are set at zero in January 2006. 


\section{Macrothink}

Panel A. July 1990 to October 2020

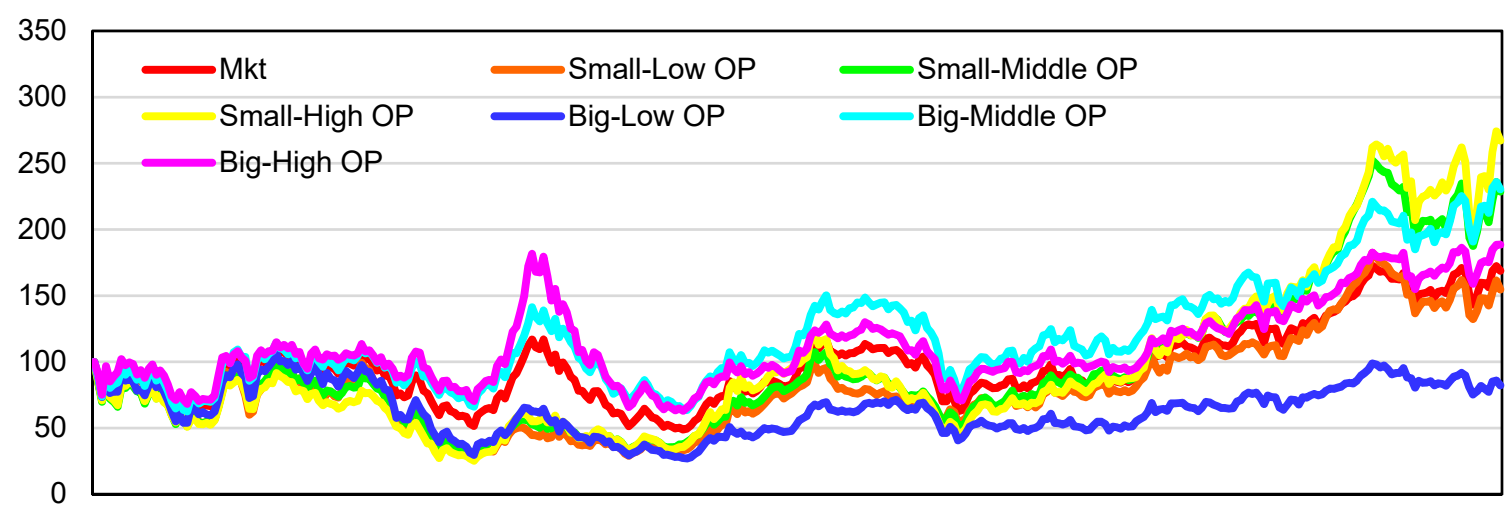

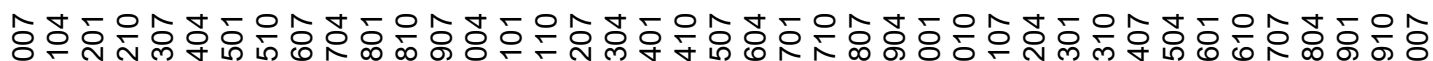

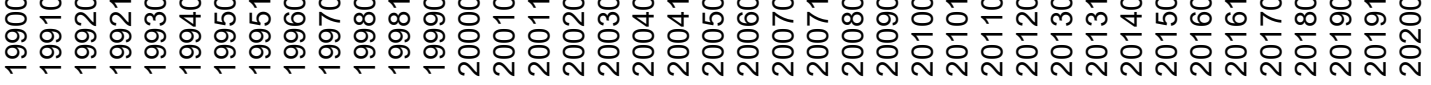

Panel B. July 1990 to December 2005

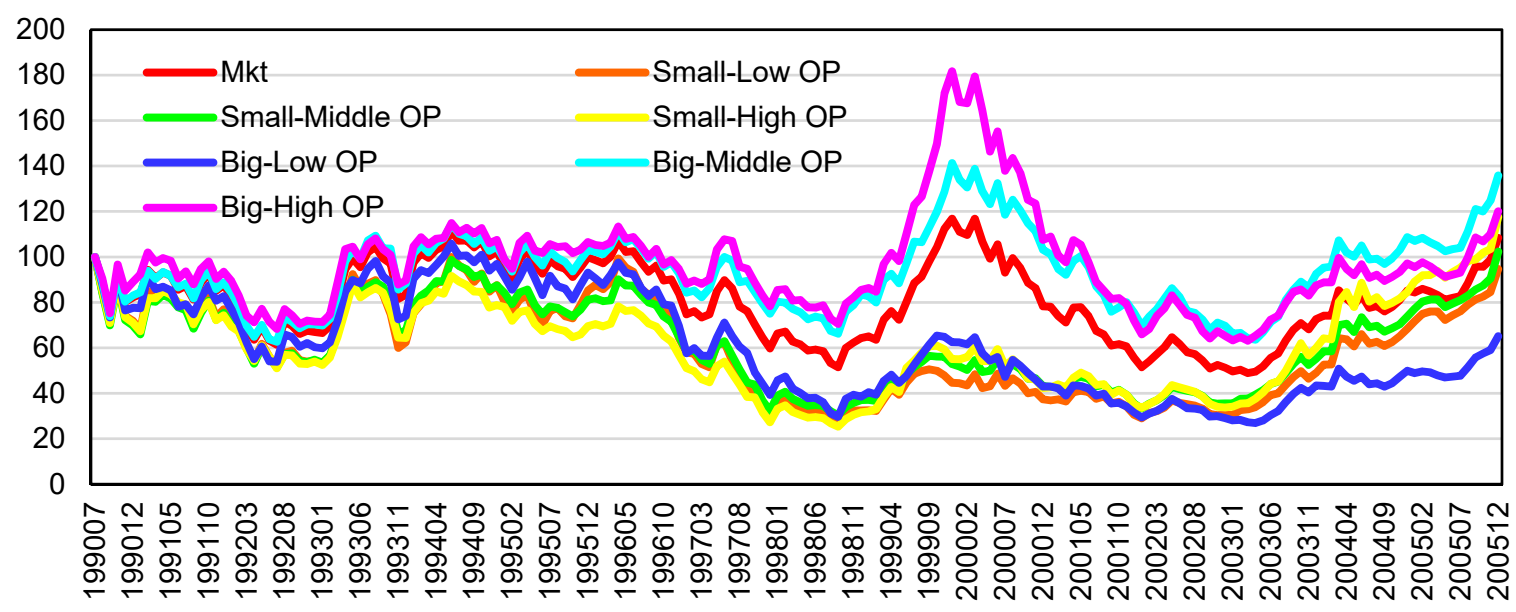

Panel C. January 2006 to October 2020

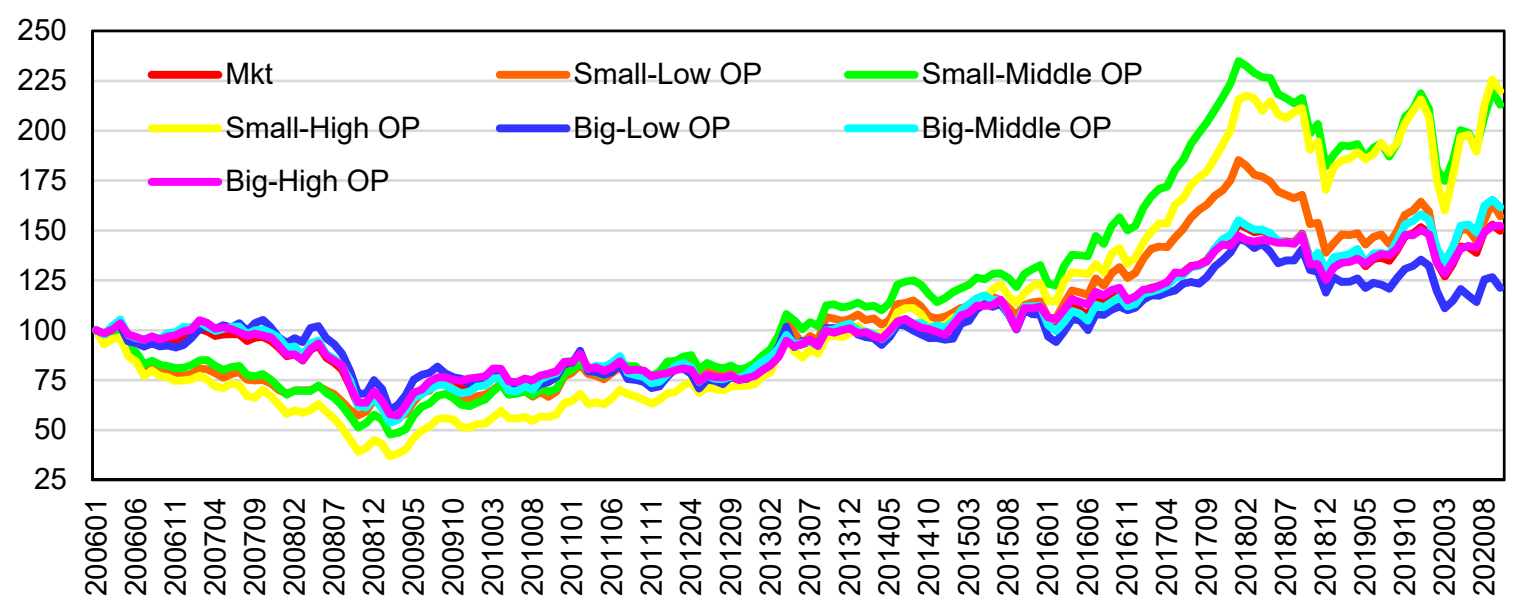

Figure 1. Time-series evolution of cumulative raw returns of size- and operating profitabilitysorted portfolios in Japan 
Panel A. July 1990 to October 2020

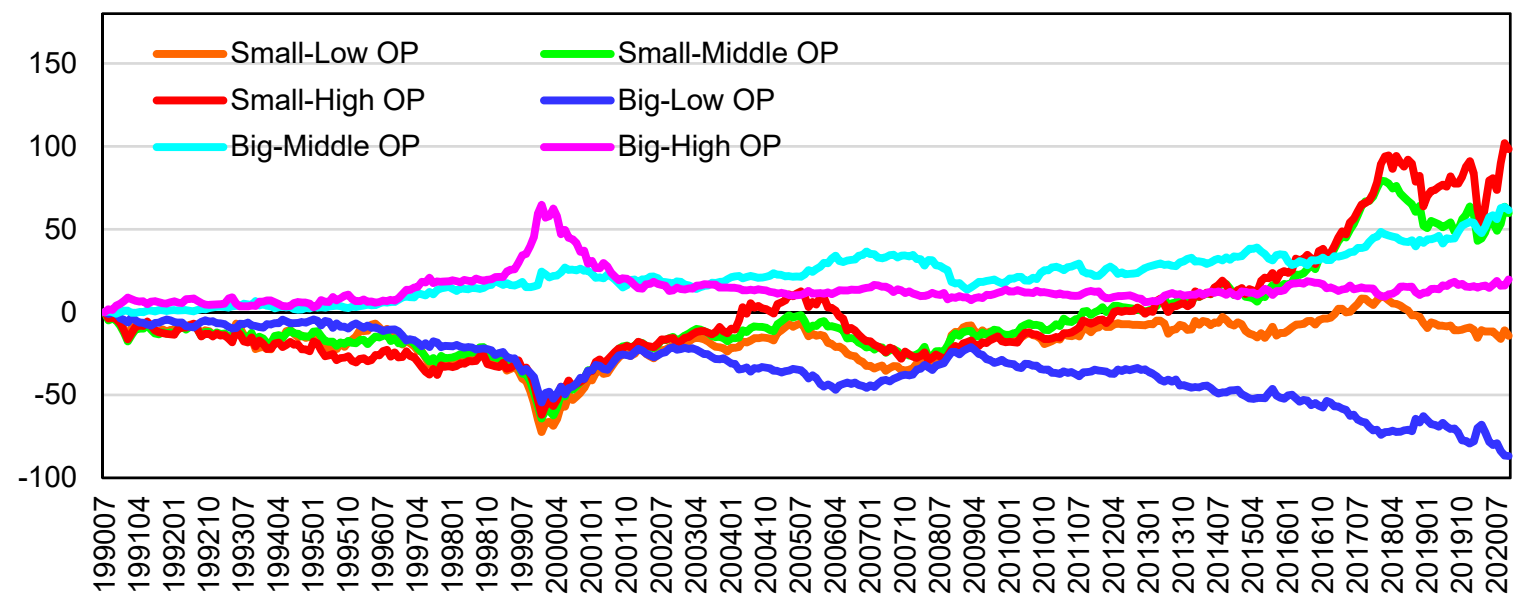

Panel B. July 1990 to December 2005

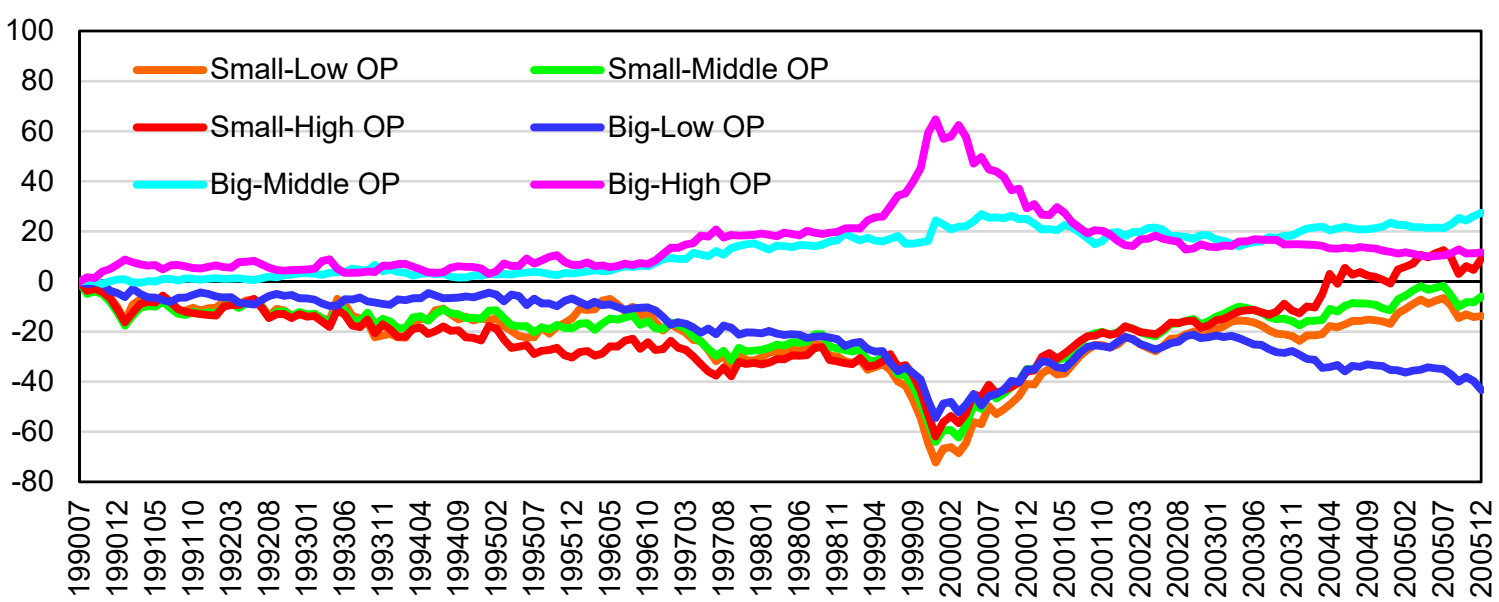

Panel C. January 2006 to October 2020

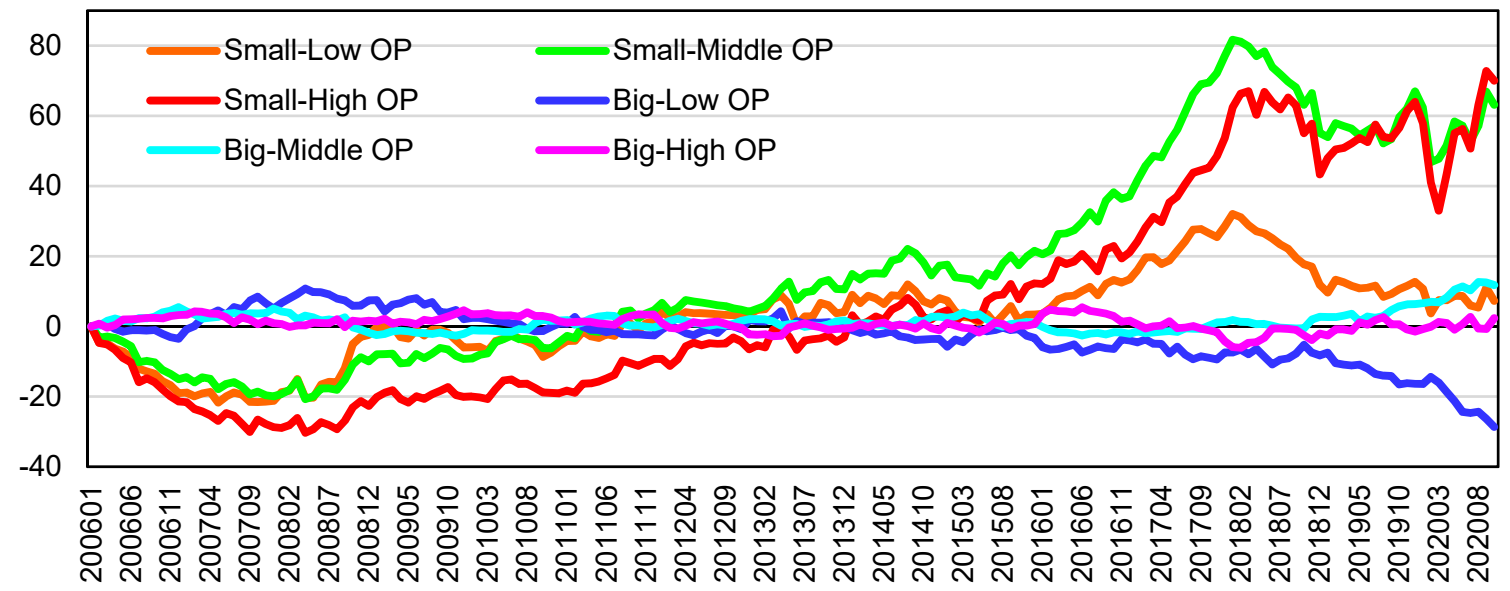

Figure 2. Time-series evolution of cumulative return premia of size- and operating profitability-sorted portfolios over the market portfolio in Japan 
Table 1. Annualized statistics for Japanese size- and operating profitability-sorted portfolio returns and return premia: Full and two sub-periods

Panel A. July 1990 to October 2020

A-1. Portfolio percentage raw return

\begin{tabular}{llllllll}
\hline & Mkt & Small- & Small- & Small- & Big- & Big- & Big- \\
& & Low & Middle & High & Low & Middle & High \\
& & OP & OP & OP & OP & OP & OP \\
\hline Return & 3.62 & 4.35 & 5.32 & 6.28 & 2.01 & 4.55 & 3.82 \\
SD & 19.46 & 23.75 & 21.77 & 23.82 & 23.03 & 18.99 & 18.96 \\
Risk premia & 1.08 & 1.80 & 2.77 & 3.74 & -0.54 & 2.01 & 1.28 \\
Sharp ratio & 0.06 & 0.08 & 0.13 & 0.16 & -0.02 & 0.11 & 0.07 \\
\hline
\end{tabular}

A-2. Portfolio percentage return premia over the market portfolio

\begin{tabular}{lllllll}
\hline & Small- & Small- & Small- & Big- & Big- & Big- \\
& Low & Middle & High & Low & Middle & High \\
& OP & OP & OP & OP & OP & OP \\
\hline Return premia & 0.72 & 1.69 & 2.66 & -1.62 & 0.93 & 0.20 \\
\hline
\end{tabular}

Panel B. July 1990 to December 2005

B-1. Portfolio percentage raw return

\begin{tabular}{llllllll}
\hline & Mkt & Small- & Small- & Small- & Big- & Big- & Big- \\
& & Low & Middle & High & Low & Middle & High \\
& & OP & OP & OP & OP & OP & OP \\
\hline Return & 3.27 & 4.29 & 4.07 & 5.45 & 1.18 & 4.41 & 3.72 \\
SD & 23.50 & 29.96 & 26.49 & 28.43 & 28.14 & 22.21 & 23.20 \\
Risk premia & -0.64 & 0.38 & 0.16 & 1.54 & -2.74 & 0.50 & -0.20 \\
Sharp ratio & -0.03 & 0.01 & 0.01 & 0.05 & -0.10 & 0.02 & -0.01
\end{tabular}


B-2. Portfolio percentage return premia over the market portfolio

\begin{tabular}{lllllll}
\hline & Small- & Small- & Small- & Big- & Big- & Big- \\
& Low & Middle & High & Low & Middle & High \\
& OP & OP & OP & OP & OP & OP \\
\hline Return premia & 1.02 & 0.80 & 2.18 & -2.09 & 1.14 & 0.45 \\
\hline
\end{tabular}

Panel C. January 2006 to October 2020

C-1. Portfolio percentage raw return

\begin{tabular}{llllllll}
\hline & Mkt & Small- & Small- & Small- & Big- & Big- & Big- \\
& & Low & Middle & High & Low & Middle & High \\
& & OP & OP & OP & OP & OP & OP \\
\hline Return & 3.99 & 4.40 & 6.62 & 7.15 & 2.88 & 4.70 & 3.93 \\
SD & 14.12 & 14.79 & 15.44 & 17.87 & 16.13 & 14.96 & 13.23 \\
Risk premia & 2.88 & 3.29 & 5.51 & 6.04 & 1.76 & 3.59 & 2.82 \\
Sharp ratio & 0.20 & 0.22 & 0.36 & 0.34 & 0.11 & 0.24 & 0.21 \\
\hline
\end{tabular}

C-2. Portfolio percentage return premia over the market portfolio

\begin{tabular}{lllllll}
\hline & Small- & Small- & Small- & Big- & Big- & Big- \\
& Low & Middle & High & Low & Middle & High \\
& OP & OP & OP & OP & OP & OP \\
\hline Return premia & 0.41 & 2.63 & 3.16 & -1.12 & 0.71 & -0.07 \\
\hline
\end{tabular}

Notes: Annualized statistics are computed from monthly data; Mkt-the Japanese overall market; SD—standard deviation values. 
Table 2. Annualized statistics for Japanese size- and operating profitability-sorted portfolio returns and return premia: Seven sub-periods

Panel A. July 1990 to June 1995

A-1. Portfolio percentage raw return

\begin{tabular}{llllllll}
\hline & Mkt & Small- & Small- & Small- & Big- & Big- & Big- \\
& & Low & Middle & High & Low & Middle & High \\
& & OP & OP & OP & OP & OP & OP \\
\hline Return & 2.59 & 0.02 & 0.95 & -1.44 & 1.66 & 3.09 & 3.89 \\
SD & 28.75 & 36.04 & 32.97 & 32.11 & 32.57 & 28.04 & 28.16 \\
Risk premia & -1.84 & -4.41 & -3.47 & -5.86 & -2.77 & -1.33 & -0.54 \\
Sharp ratio & -0.06 & -0.12 & -0.11 & -0.18 & -0.08 & -0.05 & -0.02 \\
\hline
\end{tabular}

A-2. Portfolio percentage return premia over the market portfolio

\begin{tabular}{lllllll}
\hline & Small- & Small- & Small- & Big- & Big- & Big- \\
Low & Middle & High & Low & Middle & High \\
& OP & OP & OP & OP & OP & OP \\
\hline Return premia & -2.57 & -1.64 & -4.03 & -0.93 & 0.50 & 1.30 \\
\hline
\end{tabular}

Panel B. July 1997 to June 2002

B-1. Portfolio percentage raw return

\begin{tabular}{llllllll}
\hline & Mkt & Small- & Small- & Small- & Big- & Big- & Big- \\
& & Low & Middle & High & Low & Middle & High \\
& & OP & OP & OP & OP & OP & OP \\
\hline Return & -4.86 & -6.38 & -4.82 & -0.38 & -9.64 & -1.70 & -3.29 \\
SD & 23.32 & 30.93 & 26.06 & 30.00 & 29.23 & 21.18 & 24.61 \\
Risk premia & -9.30 & -10.82 & -9.27 & -4.82 & -14.08 & -6.14 & -7.74 \\
Sharp ratio & -0.40 & -0.35 & -0.36 & -0.16 & -0.48 & -0.29 & -0.31 \\
\hline
\end{tabular}


B-2. Portfolio percentage return premia over the market portfolio

\begin{tabular}{lllllll}
\hline & Small- & Small- & Small- & Big- & Big- & Big- \\
Low & Middle & High & Low & Middle & High \\
& OP & OP & OP & OP & OP & OP \\
\hline Return premia & -1.52 & 0.03 & 4.48 & -4.78 & 3.16 & 1.56 \\
\hline
\end{tabular}

Panel C. January 2002 to December 2006

C-1. Portfolio percentage raw return

\begin{tabular}{llllllll}
\hline & Mkt & Small- & Small- & Small- & Big- & Big- & Big- \\
& & Low & Middle & High & Low & Middle & High \\
& & OP & OP & OP & OP & OP & OP \\
\hline Return & 14.68 & 20.03 & 19.66 & 21.60 & 15.51 & 14.34 & 11.95 \\
SD & 16.43 & 18.87 & 18.15 & 22.58 & 18.82 & 15.88 & 15.54 \\
Risk premia & 12.39 & 17.74 & 17.37 & 19.31 & 13.22 & 12.05 & 9.65 \\
Sharp ratio & 0.75 & 0.94 & 0.96 & 0.86 & 0.70 & 0.76 & 0.62 \\
\hline
\end{tabular}

C-2. Portfolio percentage return premia over the market portfolio

\begin{tabular}{lllllll}
\hline & Small- & Small- & Small- & Big- & Big- & Big- \\
& Low & Middle & High & Low & Middle & High \\
& OP & OP & OP & OP & OP & OP \\
\hline Return premia & 5.35 & 4.98 & 6.92 & 0.83 & -0.34 & -2.74 \\
\hline
\end{tabular}

Panel D. January 2007 to December 2011

D-1. Portfolio percentage raw return

$\begin{array}{lllllll}\text { Mkt } & \text { Small- } & \text { Small- } & \text { Small- } & \text { Big- } & \text { Big- } & \text { Big- } \\ \text { Low } & \text { Middle } & \text { High } & \text { Low } & \text { Middle } & \text { High } \\ \text { OP } & \text { OP } & \text { OP } & \text { OP } & \text { OP } & \text { OP }\end{array}$




\begin{tabular}{lccccccc} 
Return & -3.72 & 0.83 & 0.89 & -0.78 & -3.30 & -4.67 & -3.61 \\
SD & 16.68 & 15.30 & 17.02 & 19.90 & 18.77 & 17.85 & 16.02 \\
Risk premia & -5.00 & -0.45 & -0.38 & -2.05 & -4.58 & -5.95 & -4.88 \\
Sharp ratio & -0.30 & -0.03 & -0.02 & -0.10 & -0.24 & -0.33 & -0.30 \\
\hline
\end{tabular}

D-2. Portfolio percentage return premia over the market portfolio

\begin{tabular}{lllllll}
\hline & Small- & Small- & Small- & Big- & Big- & Big- \\
& Low & Middle & High & Low & Middle & High \\
& OP & OP & OP & OP & OP & OP \\
\hline Return premia & 4.55 & 4.61 & 2.94 & 0.42 & -0.95 & 0.11 \\
\hline
\end{tabular}

Panel E. April 2010 to March 2015

E-1. Portfolio percentage raw return

\begin{tabular}{llllllll}
\hline & Mkt & Small- & Small- & Small- & Big- & Big- & Big- \\
& & Low & Middle & High & Low & Middle & High \\
& & OP & OP & OP & OP & OP & OP \\
\hline Return & 7.85 & 10.47 & 12.41 & 15.01 & 6.95 & 8.96 & 6.65 \\
SD & 13.21 & 15.00 & 13.87 & 14.88 & 16.45 & 13.78 & 11.91 \\
Risk premia & 7.81 & 10.44 & 12.37 & 14.97 & 6.91 & 8.92 & 6.61 \\
Sharp ratio & 0.59 & 0.70 & 0.89 & 1.01 & 0.42 & 0.65 & 0.55 \\
\hline
\end{tabular}

E-2. Portfolio percentage return premia over the market portfolio

\begin{tabular}{lllllll}
\hline & Small- & Small- & Small- & Big- & Big- & Big- \\
& Low & Middle & High & Low & Middle & High \\
& OP & OP & OP & OP & OP & OP \\
\hline Return premia & 2.63 & 4.57 & 7.16 & -0.90 & 1.11 & -1.20 \\
\hline
\end{tabular}

Panel F. April 2015 to March 2020 
F-1. Portfolio percentage raw return

\begin{tabular}{llllllll}
\hline & Mkt & Small- & Small- & Small- & Big- & Big- & Big- \\
& & Low & Middle & High & Low & Middle & High \\
& & OP & OP & OP & OP & OP & OP \\
\hline Return & 3.86 & 4.66 & 8.13 & 8.34 & 2.19 & 4.28 & 4.06 \\
SD & 12.88 & 13.89 & 14.43 & 16.07 & 14.26 & 13.44 & 12.24 \\
Risk premia & 2.81 & 3.61 & 7.07 & 7.28 & 1.13 & 3.22 & 3.00 \\
Sharp ratio & 0.22 & 0.26 & 0.49 & 0.45 & 0.08 & 0.24 & 0.24 \\
\hline
\end{tabular}

F-2. Portfolio percentage return premia over the market portfolio

\begin{tabular}{lllllll}
\hline & Small- & Small- & Small- & Big- & Big- & Big- \\
& Low & Middle & High & Low & Middle & High \\
& OP & OP & OP & OP & OP & OP \\
\hline Return premia & 0.08 & 4.26 & 4.48 & -1.67 & 0.42 & 0.19 \\
\hline
\end{tabular}

Panel G. January 2020 to October 2020

G-1. Portfolio percentage raw return

\begin{tabular}{llllllll}
\hline & Mkt & Small- & Small- & Small- & Big- & Big- & Big- \\
& & Low & Middle & High & Low & Middle & High \\
& & OP & OP & OP & OP & OP & OP \\
\hline Return & 0.18 & -3.04 & -0.28 & 7.03 & -11.29 & 4.49 & 2.74 \\
SD & 18.98 & 22.66 & 24.71 & 32.14 & 20.31 & 19.96 & 15.99 \\
Risk premia & -0.34 & -3.55 & -0.79 & 6.52 & -11.81 & 3.97 & 2.22 \\
Sharp ratio & -0.02 & -0.16 & -0.03 & 0.20 & -0.58 & 0.20 & 0.14 \\
\hline
\end{tabular}

G-2. Portfolio percentage return premia over the market portfolio

Small- Small- Small- Big- Big- Big-




\begin{tabular}{lllllll}
\hline & Low & Middle & High & Low & Middle & High \\
& OP & OP & OP & OP & OP & OP \\
\hline Return premia & -3.22 & -0.46 & 6.85 & -11.47 & 4.31 & 2.56 \\
\hline
\end{tabular}

Notes: Annualized statistics are computed from monthly data; Mkt-the Japanese overall market; SD—standard deviation values.

\section{Key Findings}

We calculate and present several statistics for our full sample period, the former half sub-period, and latter half sub-period in Table 1. We also exhibit the same statistics for our seven subperiods in Table 2. Documenting our key findings suggested from Table 1, first, as Panel A of this table shows, (1) for our full sample period, the return of the Small-High OP portfolio is the highest, and the return of the Small-Middle OP portfolio is the second highest. Next, as Panel B of this table exhibits, (2) for our former half period, the return of the Small-High OP portfolio is the highest, and that of the Big-Middle OP portfolio is the second highest. Moreover, as Panel $\mathrm{C}$ of this table shows, (3) for our latter half period, the return of the Small-High OP portfolio is the highest, and that of the Small-Middle OP portfolio is the second highest.

Further, documenting our key findings suggested from Table 2, first, as Panel A of this table shows, (1) for the period comprising the collapse of stock price bubble in Japan, the return of the Big-High OP portfolio is the highest, and the return of the Big-Middle OP portfolio is the second highest. Next, as Panel B of this table displays, (2) for the period comprising the IT bubble, the return of the Small-High OP portfolio is the highest, and that of the Big-Middle OP portfolio is the second highest. In addition, as Panel C of this table exhibits, (3) for the period in which Japan's QE boosted Japanese equity prices, the return of the Small-High OP portfolio is the highest, and that of the Small-Low OP portfolio is the second highest.

Moreover, as Panel D of this table indicates, (4) for the period comprising the US subprime crisis and the collapse of Lehman Brothers, the return of the Small-Middle OP portfolio is the highest, and that of the Small-Low OP portfolio is the second highest. Fifth, as Panel E shows, (5) for the period comprising the Great East Japan Earthquake, the return of the Small-High OP portfolio is the highest, and that of the Small-Middle OP portfolio is the second highest. In addition, as Panel F displays, (6) for the period of the BOJ's successive monetary easing policies, the return of the Small-High OP portfolio is the highest, and that of the Small-Middle OP portfolio is the second highest. Finally, as Panel G shows, (7) for our latest period including the effect of COVID-19, the return of the Small-High OP portfolio is the highest, and the BigMiddle OP portfolio is the second highest.

\section{Conclusions}

The objective of this study was to take a brief look at returns and return premia of Japanese size- and operating profitability-sorted equity portfolios. This study computed key statistics both for the full, former half, and latter half periods and for different seven sub-periods. Notably, 
as this study employed data in US dollars and derived the key statistics, these should be highly useful for both academic researchers and many international investors.

As a result of our examinations, we conclude that generally, the effects of size and operating profitability were continuously recognized in the Japanese equity market; however, to gain these effects to the maximum, both market timing and investment horizon are vital. This is because business and economic circumstances greatly affect the performance of Japanese sizeand operating profitability-sorted portfolios. More specifically, as our graphs in Figure 1 and the statistics in Table 1 indicated, the size effect was much stronger in our latter half sub-period; while the operating profitability effect was similarly seen in both our former half and latter half sub-periods. In short, as noted, the market timing of starting and ending the investment is vital to effectively gain the effects of size and operating profitability in the Japanese equity market.

Though we explained our results by especially focusing on our key findings; as demonstrated in Tables 1 and 2, this study provided ample useful information regarding the Japanese sizeand operating profitability-sorted portfolios for almost 30 years. All these statistics and measures for both the full period and many other significant sub-periods shall be much informative for not only academic researchers but also industrial practitioners.

Finally, we note that according to Fama and French (2015), their operating profitability measure is defined as "annual revenues minus cost of goods sold, interest expense, and selling, general, and administrative expenses (divided by book equity)." The more detailed asset pricing research by focusing on other measures of corporate profitability may be one of our future works.

\section{Acknowledgements}

I am grateful to the repeated kind article invitation from this journal, and I also particularly appreciate Lucy $\mathrm{Xu}$ for her kind editorial assistance to my paper. In addition, I thank anonymous reviewers for their highly supportive comments, and I also appreciate the Chuo University Personal Research Grant and a Grant-in-Aid for Scientific Research from the Japan Society for the Promotion of Science for the generous financial assistance to my research. Finally, I deeply thank all the editors of this journal for their kind attention to and skillful editorship of my paper.

\section{References}

Chan, L. K. C., Hamao, Y., \& Lakonishok, J. (1991). Fundamentals and stock returns in Japan. Journal of Finance, 46, 1739-1764. http://dx.doi.org/10.2307/2328571

Chen, E. T., \& Ho, J. C. (2020). Mispricing and the five-factor model under different market sentiments. Heliyon, 6, e04191. https://doi.org/10.1016/j.heliyon.2020.e04191

Fama, E. F., \& French, K. R. (1993). Common risk factors in the returns on stocks and bonds. Journal of Financial Economics, 33, 3-56. http://dx.doi.org/10.1016/0304-405X(93)90023-5

Fama, E. F., \& French, K. R. (2012). Size, value, and momentum in international stock returns. Journal of Financial Economics, 105, 457-472. https://doi.org/10.1016/j.jfineco.2012.05.011 


\section{Macrothink}

Journal of Management Research

ISSN 1941-899X 2021, Vol. 13, No. 2

Fama, E. F., \& French, K. R. (2015). A five-factor asset pricing model. Journal of Financial Economics, 116, 1-22. http://dx.doi.org/10.1016/j.jfineco.2014.10.010

Fama, E. F., \& French, K. R. (2017). International tests of a five-factor asset pricing model. Journal of Financial Economics, 123, 441-463. https://doi.org/10.1016/j.jfineco.2016.11.004

Jareño, F., de la O González, M., \& Escolástico, A. M. (2020). Extension of the Fama and French model: A study of the largest European financial institutions. International Economics, 164, 115-139. https://doi.org/10.1016/j.inteco.2020.09.001

Leite, A. L., Klotzle, M. C., Pinto, A. C. F., \& da Silveira Barbedo, C. H. (2020). The FamaFrench's five-factor model relation with interest rates and macro variables. North American Journal of Economics and Finance, 53, 101197. https://doi.org/10.1016/j.najef.2020.101197

Lin, Q. (2017). Noisy prices and the Fama-French five-factor asset pricing model in China. Emerging Markets Review, 31, 141-163. http://dx.doi.org/10.1016/j.ememar.2017.04.002

Tsuji, C. (2012a). Do industries contain predictive information for the Fama-French factors? Quantitative Finance, 12, 969-991. https://doi.org/10.1080/14697681003762271

Tsuji, C. (2012b). Positive return premia in Japan. Quantitative Finance, 12, 345-367. https://doi.org/10.1080/14697688.2010.541485

Ülkü, N. (2017). Monday effect in Fama-French's RMW factor. Economics Letters, 150, 4447. http://dx.doi.org/10.1016/j.econlet.2016.10.031 